\title{
SPELEN MET VERSIERING EN VORM: JAPANS KERAMIEK EN LAK IN RINPA-STIJL
}

De stad Kyoto in midden-Japan, de keizerlijke residentie sinds de $8^{\mathrm{e}}$ eeuw, is door de eeuwen heen een centrum van de kunsten geweest. Al gelijk na de ingebruikname als zetel in 794 ontwikkelde er zich een bloeiende hofcultuur. Zij bracht verfijnde literatuur voort en het pas geïntroduceerde Boeddhisme zorgde voor een veelvoud van tempels, met de bijbehorende sculptuur, schilderkunst en religieuze voorwerpen. Het is logisch dat een dergelijk centrum een aanzuigende werking had op handwerkslieden, die hofelite en entourage voorzagen van gebruiksartikelen als textiel, lakwerk en keramiek. Deze bundeling van krachten op één plek veroorzaakte een levendige uitwisseling van motieven en vormen tussen de verschillende kunstvormen onderling. Zo kon het zijn dat kimono-ontwerpen de versiering op keramiek inspireerden, stijlen uit de schilderkunst werden overgenomen op lakwerk en literatuur in alle media zijn neerslag vond. Dit kon zijn als inspiratiebron voor motieven die verwezen naar passages uit een roman, maar ook letterlijk, zoals gekalligrafeerde gedichten die werden afgebeeld op textiel, of werden ingelegd in parelmoer op lakwerk (afb. 1). De karakters op deze schrijfdoos vormen, zich slingerend over zowel de deksel als de doos zelf, een $10^{\mathrm{e}}$-eeuws gedicht over de herfst. Het refereert aan de bladeren van de plant hagi (Lespedeza bicolor), die weer als motief voor het achtergrondpatroon op de deksel werden gebruikt. Deze doos werd waarschijnlijk gemaakt aan het eind van de $17^{\mathrm{e}}$ of begin van de $18^{\mathrm{c}}$ eeuw, toen er een heropleving was van de interesse voor de hofcultuur van de Heian-tijd (794-1192).

Het was vooral de Rinpa-stijl die veel gebruik maakte van verwijzingen naar de klassieke hofliteratuur. De naam Rinpa is ontleend aan het tweede karakter van de naam van Ogata Korin (1658-1716), die de stijl aan het eind van de 17 e eeuw nieuw leven inblies. Een eeuw eerder waren twee pioniers van de stijl al aktief geweest, Hon'ami Koetsu (1558-1637) en Tawaraya Sotatsu (?-1643), maar het was Korin die Rinpa als stijl ingang deed vinden. Naast het citeren van klassieke literatuur kenmerkt de stijl zich door het stileren van motieven tot decoratie-elementen, die gecombineerd worden tot een rijk versierd oppervlak. Details zijn vaak uitvergroot en geïsoleerd weergegeven, en worden abrupt afgesneden door de rand van het vlak of lopen over de zijden van een driedimensonaal voorwerp heen. Rinpa slechtte ook nog meer dan voorheen de grenzen tussen de kunstvormen onderling. Kunstenaars werkten vaak in eerste instantie als schilder, maar waren daarnaast ook aktief als ontwerper voor keramiek, lakwerk of textiel. Rinpa is te gevarieerd en zonder vaste doctrine om een school genoemd te worden. Het is meer een lijn die door de Edo-periode (1600-1868) heen loopt en die met tussenpozen door een aantal artiesten is opgepakt en verder ontwikkeld. 


\section{Afbeelding 1}

Schrijfdoos, lak met versiering in goud en parelmoerinleg

h. $3,8 \mathrm{~cm}$., b. $27,6 \mathrm{~cm}$., d. $25,7 \mathrm{~cm}$.

Japan, eind $17^{\mathrm{e}}$.

begin $18^{e}$ eeuw

Rijksmuseum, legaat

Westendorp-Osieck, inv.nr. AK-MAK-141

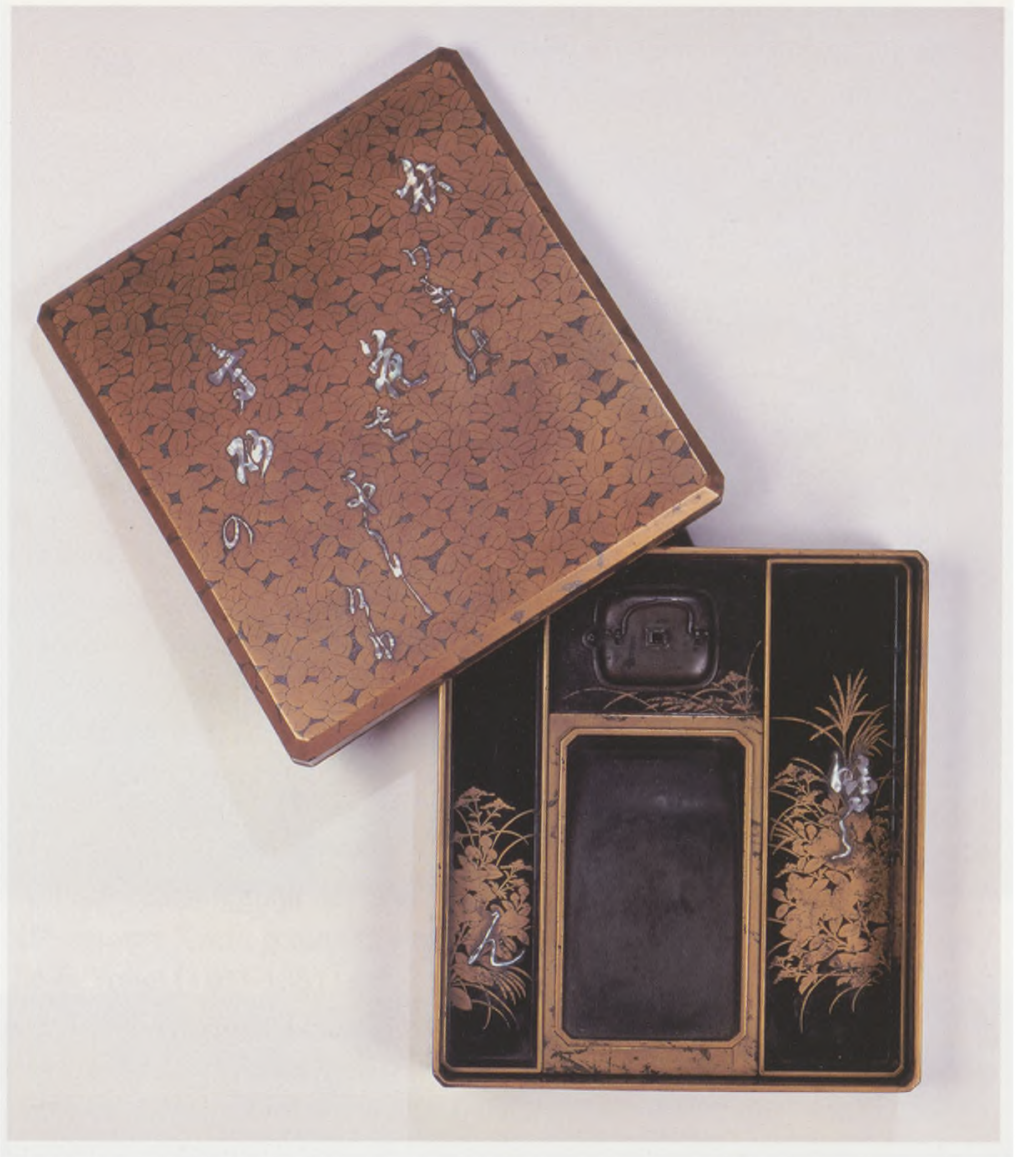

Afbeelding 2

Doos, lak op hout Signatuur en zegel van Ogawa Haritsu (16631747)

h. $9 \mathrm{~cm}$., b. $18,8 \mathrm{~cm}$. Japan, $18^{\text {e eeuw }}$ Rijksmuseum, legaat Westendorp-Osieck, inv.nr. AK-MAK-886

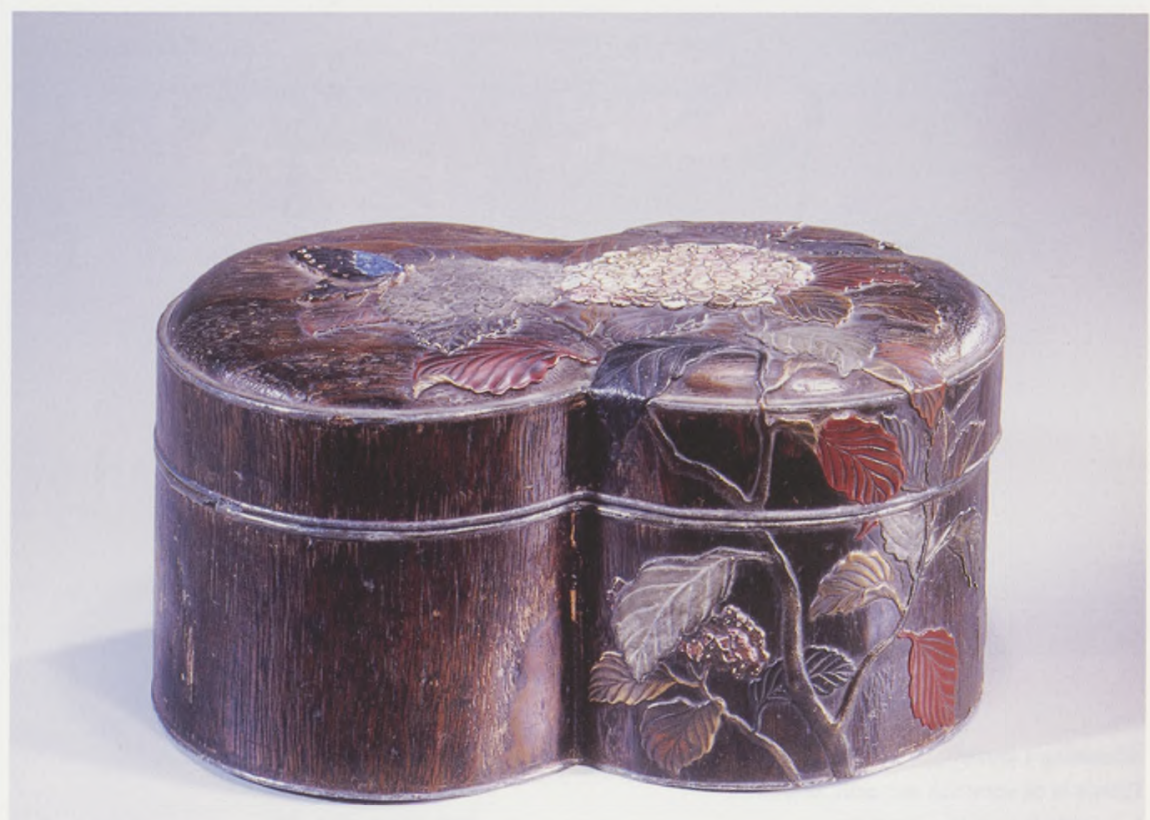




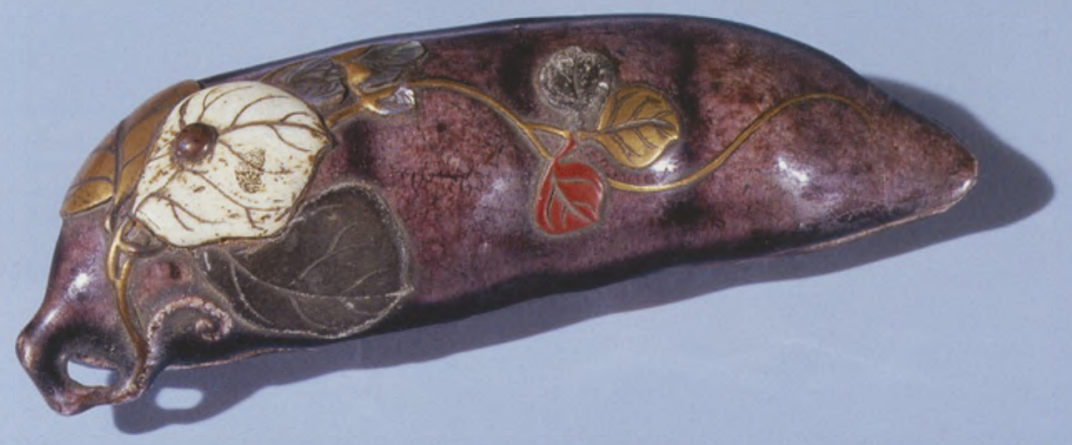

Afbeelding 3 (boven)

Doosje in de vorm van een peul, aardewerk

h. $2,5 \mathrm{~cm}$., b. $11,0 \mathrm{~cm}$., d. $3,0 \mathrm{~cm}$.

Japan, $19^{\mathrm{e}}$ eeuw

Rijksmuseum, legaat Westendorp-Osieck, inv.nr. AK-MAK-710

\section{Afbeelding 4}

Kom, steengoed

Seifu Yohei (1803-1861)

h. 7,8 cm., diam. $15,5 \mathrm{~cm}$. Japan, $19^{e}$ eeuw

Rijksmuseum, legaat Westendorp-Osieck, inv.nr. AK:MAK 8 : 86 G 6 access 
Ogawa Haritsu (1663-1747) was een van de ontwerpers die sterk door Rinpa werd beïnvloed. Na een carrière in andere kunstvormen schakelde hij pas op latere leeftijd over op het ontwerpen van lakwerk. Een mogelijk door hem vormgegeven doos (afb. 2) laat duidelijk de Rinpa-invloed zien. Schijnbaar zonder acht te slaan op de vorm heeft hij het ontwerp van de hortensia met vlinder over de doos 'gedrapeerd'. Haritsu, ook wel Ritsuo genoemd, was een echte vernieuwer. Hij introduceerde onder meer het gebruik van een ondergrond van onversierd ruw hout met daarop een ingelegde decoratie in verschillende kleuren en materialen.

Hetzelfde type versiering met inleg is te vinden op het kleine wierookdoosje van keramiek op afbeelding 3 . Het is kunstig gemaakt in de vorm van een peul, die bol staat van de rondingen van de erwten binnenin. Op een ondergrond van een fijn paars glazuur is een uitloper van de plant aangebracht in ingelegd rood- en goudlak, parelmoer, tin en been. Het twijgje lijkt een uitloper te zijn van de plant waaraan de peul groeit. De aanhechting van de peul gaat met een krul over in het bladertakje, waar op een van de bladeren nog een klein lieveheersbeestje is gezet. Het is daarmee een mooi voorbeeld van de speelsheid waarmee omgegaan werd met perspectief en materiaal.

Net als waarschijnlijk het doosje is ook de kom op afbeelding 4 in het $19^{e}$-eeuwse Kyoto gemaakt, eveneens in een stijl die dicht bij Rinpa ligt. Seifu Yohei (1803-1861) gaf de op het wiel gedraaide kom een onregelmatige rand mee, die met een donkerbruin glazuur is afgewerkt. Yohei was een leerling van Nin'ami Dohachi (1783-1855), een van een groep van pottenbakkers in Kyoto, die elk op een andere manier richting gaven aan het Kyoto keramiek. Dohachi werkte in veel verschillende stijlen en is bekend om zijn werk in kleurige emails op het glazuur. Deze kom van Yohei staat dicht bij het werk van zijn leermeester. Net als Dohachi heeft hij in een vrije, spontane stijl de rode bladeren en een besneeuwde pijnboomtak geschilderd, alweer doorlopend over het vlak van binnen- en buitenkant van de kom.

Alle bovenstaande voorwerpen zijn afkomstig uit de verzameling van Herman Karel Westendorp (1868-1941), een van de oprichters van de Vereniging, wiens legaat in 1968 in de collectie kwam. Het is opvallend hoe Westendorp er uitstekend in geslaagd is een collectie op te bouwen aan de hand waarvan de verbanden in de Japanse kunst zijn te illustreren. Zonder problemen is het bovenstaande naar alle kanten uit te breiden met meer voorbeelden van hoge kwaliteit, exemplarisch voor een stijl of kunstenaar, zodat in skeletvorm een indruk kan worden gegeven van de ontwikkeling van Japanse kunst.

Daarmee voldoet zijn manier van verzamelen bij uitstek aan de doelstelling van de Vereniging: het verspreiden van de kennis over Aziatische kunst aan de hand van een collectie van representatieve hoogtepunten van de kunsten uit Azië. 


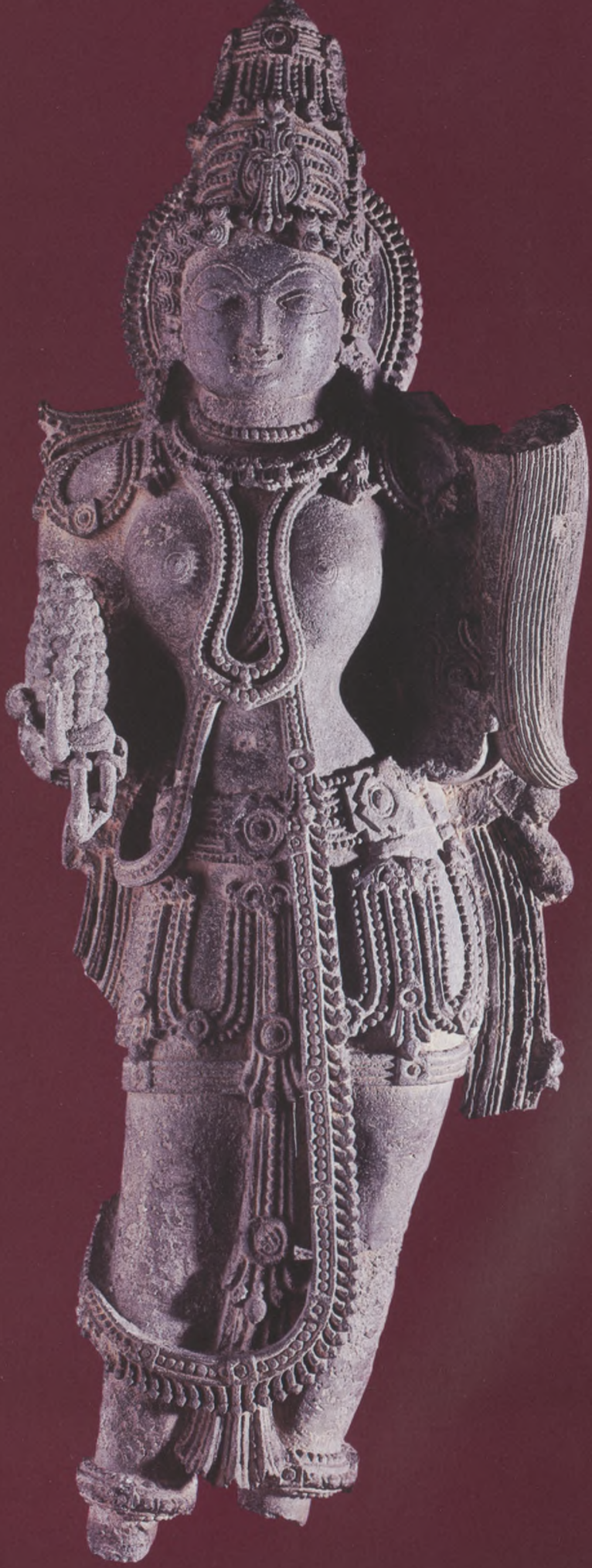

